\title{
Dormant non-culturable Mycobacterium tuberculosis retains stable low-abundant mRNA
}

Dmitriy V. Ignatov ${ }^{1 *+}$, Elena G. Salina ${ }^{2 \dagger}$, Mikhail V. Fursov ${ }^{2}$, Timofey A. Skvortsov²,3 ${ }^{2,}$ Tatyana L. Azhikina ${ }^{1}$ and Arseny S. Kaprelyants ${ }^{2}$

\begin{abstract}
Background: Dormant Mycobacterium tuberculosis bacilli are believed to play an important role in latent tuberculosis infection. Previously, we have demonstrated that cultivation of $\mathrm{M}$. tuberculosis in $\mathrm{K}^{+}$-deficient medium resulted in generation of dormant cells. These bacilli were non-culturable on solid media (a key feature of dormant M. tuberculosis in vivo) and characterized by low metabolism and tolerance to anti-tuberculosis drugs. The dormant bacteria demonstrated a high potential to reactivation after $\mathrm{K}^{+}$reintroduction even after prolonged persistence under rifampicin. In this work, we studied the transcriptome and stability of transcripts in persisting dormant bacilli under arrest of mRNA de novo synthesis.
\end{abstract}

Results: RNA-seq-based analysis of the dormant non-culturable population obtained under rifampicin exposure revealed a 30-50-fold decrease of the total mRNA level, indicating global transcriptional repression. However, the analysis of persisting transcripts displayed a cohort of mRNA molecules coding for biosynthetic enzymes, proteins involved in adaptation and repair processes, detoxification, and control of transcription initiation. This 'dormant transcriptome' demonstrated considerable stability during M. tuberculosis persistence and mRNA de novo synthesis arrest. On the contrary, several small non-coding RNAs showed increased abundance on dormancy. Interestingly, M. tuberculosis entry into dormancy was accompanied by the cleavage of $23 \mathrm{~S}$ ribosomal RNA at a specific point located outside the ribosome catalytic center.

Conclusions: Dormant non-culturable M. tuberculosis bacilli are characterized by a global transcriptional repression. At the same time, the dormant bacilli retain low-abundant mRNAs, which are considerably stable during in vitro persistence, reflecting their readiness for translation upon early resuscitation steps. Increased abundance of non-coding RNAs on dormancy may indicate their role in the entry into and maintenance of $M$. tuberculosis dormant non-culturable state.

Keywords: Mycobacterium tuberculosis, Dormancy, Non-culturable cells, RNA-seq, Transcriptome

\section{Background}

Despite many years of thorough investigations, the molecular basis of latent tuberculosis (LTB) infection remains elusive. M. tuberculosis subpopulation associated with latent infection in humans is believed to be in a dormant state characterized by low metabolic status

\footnotetext{
* Correspondence: dima.ignatov@gmail.com

${ }^{\dagger}$ Equal contributors

'Shemyakin and Ovchinnikov Institute of Bioorganic Chemistry, Russian Academy of Sciences, 117997, Miklukho-Maklaya 16/10, GSP-7, Moscow, Russian Federation

Full list of author information is available at the end of the article
}

and transient inability to grow and proliferate [1-4]. The modeling of this specific physiological state has been attempted over years both in vivo [5-9] and in vitro [10-18]. However, in vitro models had limited success, because dormant $M$. tuberculosis bacilli obtained from the majority of these models were fully culturable, whereas mycobacteria isolated from in vivo models of LTB infection were in non-culturable (NC) state $[3,19]$.

We have recently identified $\mathrm{K}^{+}$deficiency as a triggering factor to generate dormant $M$. tuberculosis bacilli that were $\mathrm{NC}$ on solid medium. This $M$. tuberculosis 
population was morphologically distinct, and exhibited tolerance to cell wall-targeting antimicrobial agents. These cells were able to reverse quickly to metabolically active state after $\mathrm{K}^{+}$re-introduction [20]. $\mathrm{K}^{+}$deficiency is a severe stress factor, because $\mathrm{K}^{+}$balance is crucial for many cellular functions, including maintenance of intracellular $\mathrm{pH}$, osmotic pressure, electrochemical gradient, protonmotive force, and activity of the $\mathrm{Na}^{+} / \mathrm{K}^{+}$-transporting ATPase in both eukaryotes and prokaryotes [21-23]. Consequently, the changes in $\mathrm{K}^{+}$availability may induce bacterial responses leading to dormancy and non-culturability, which facilitate long-term survival of M. tuberculosis in vivo [20].

Transcriptome profiling of NC mycobacteria by microarray technique revealed downregulation of genes associated with central metabolic processes (e.g., switch of C-metabolism to the glyoxylate shunt, repression of proton-pumping type I NADH dehydrogenase and enzymes of the electron transport chain, and inhibition of ATP synthesis). On the contrary, the genes coding for the uncoupled non-proton-pumping $\mathrm{NADH}$ dehydrogenase II ( $n d h)$ and nitrate reductases (narG, narH) were significantly induced in NC $M$. tuberculosis, suggesting that $\mathrm{K}^{+}$limitation prevents mycobacteria from effectively using proton-motive force generated by respiration, thus driving them to utilize NADH dehydrogenase II and alternative electron acceptors. Moreover, a number of genes implicated in amino acid catabolism were upregulated, and the biosynthetic pathways for fatty acids and mycolic acids were downregulated. This suggests a switch to primary metabolites (including amino acids) as a main carbon source, and indicates unique metabolic adaptation of M. tuberculosis to the NC state [20].

A general problem for the modeling of $M$. tuberculosis dormancy in vitro is the heterogeneity of the bacterial population, which contains cells of different physiological status [24]. Therefore, the elimination of metabolically active cells is a prerequisite for establishing a model of $M$. tuberculosis dormancy. To remove a subpopulation of metabolically active cells $\left(1 \times 10^{3}\right.$ cells ml $\left.^{-1}\right)$ remaining in the population of dormant mycobacteria generated by $\mathrm{K}^{+}$deficiency and to obtain a homogeneous population of $\mathrm{NC}$ cells, a 15 -day $\mathrm{K}^{+}$-starved $M$. tuberculosis culture was treated with a moderate concentration of rifampicin $\left(5 \mu \mathrm{g} \mathrm{ml}^{-1}\right)$, which eliminated dividing cells [25], but did not affect the viability of dormant mycobacteria [15]. As a result, a so-called 'zero-CFU' ('zero - colony forming units') population of NC M. tuberculosis was obtained. The 'zero-CFU' population was completely unable to grow on solid medium but retained full potential to recover to physiologically active state, as evidenced by the Most Probable Number (MPN) assay [25]. This highly homogeneous NC M. tuberculosis population is much more suitable for transcriptome profiling. Elucidation of specific metabolic processes involved in maintenance of dormant state and preservation of $M$. tuberculosis viability may improve our understanding of LTB infection in humans.

A recently introduced RNA sequencing (RNA-seq) technology based on next-generation sequencing (NGS) overcomes most limitations characteristic for microarray assays. Unlike microarrays, RNA-seq technology does not require transcript-specific probes and allows detection of non-coding transcripts; moreover, RNA-seq determines gene expression levels as digital values [26]. Thus, RNA-seq is a suitable approach for the reliable analysis of dormant transcriptomes with very low mRNA levels.

In this study, we present, for the first time, RNA-seq analysis of the dormant NC M. tuberculosis population obtained under $\mathrm{K}^{+}$deficiency, which is characterized by a 'zero-CFU' phenotype and high (up to $1 \times 10^{7}$ cells ml $^{-1}$ ) recovery potential. We compared transcriptional adaptation of M. tuberculosis at different stages of dormancy, including the prolonged 'zero-CFU' state. Dormant $M$. tuberculosis transcriptome was found to be enriched in small non-coding regulatory RNA molecules. Despite a negligible level of metabolic activity, dormant mycobacteria of the 'zero-CFU' phenotype were found to express certain levels of individual transcripts, which were stable in the NC state for at least several days. Protein-coding transcripts stabilized in dormant NC cells could be utilized during further resuscitation steps.

\section{Results}

\section{Modeling non-culturability}

We have recently developed an in vitro model of NC $M$. tuberculosis by culturing mycobacteria in $\mathrm{K}^{+}$-deficient conditions. After 40 days of incubation, $\mathrm{NC}$ mycobacteria were characterized by distinctive morphology and tolerance to cell wall-targeting antibiotics. However these cells were susceptible to rifampicin [20]. The susceptibility of NC mycobacteria to rifampicin may probably be explained by the presence of susceptible subpopulation of active cells remaining in the culture (about $1 \times 10^{3}-10^{4}$ cells $\mathrm{ml}^{-1}$ ). Therefore, to enrich NC population and remove dividing cells, rifampicin $\left(5 \mu \mathrm{g} \mathrm{ml}^{-1}\right)$ was added to M. tuberculosis cultures $\mathrm{K}^{+}$-starved for 14 days [25], which resulted in a gradual decrease in the number of culturable mycobacteria until it reached zero after 10 days of incubation with rifampicin (Fig. 1a). NC cells with the 'zero-CFU' phenotype demonstrated high ability to recover metabolic activity and proliferate in the resuscitation medium (up to $2 \times 10^{7}$ cell $\mathrm{ml}^{-1}$ ), as evidenced by the MPN assay, and previously have been successfully used for screening of drugs targeting nonreplicating mycobacteria [25]. 

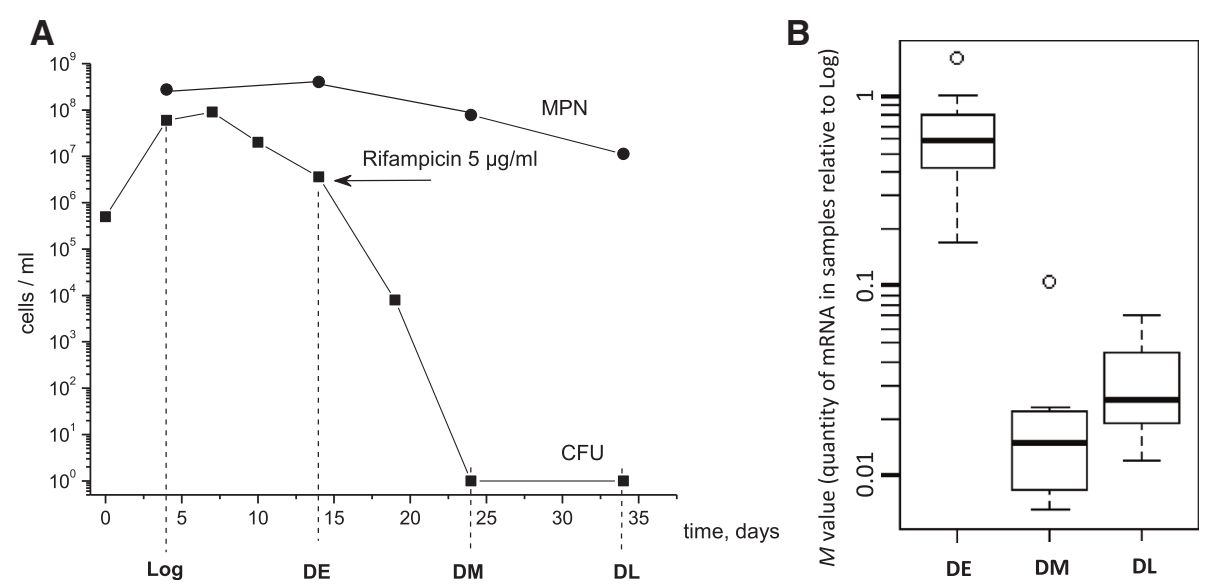

Fig. 1 Samples used for RNA-seq analysis. a Experimental flow. Formation of a 'zero-CFU' M. tuberculosis population under $\mathrm{K}^{+}$deficiency and a moderate concentration of rifampicin $\left(5 \mu \mathrm{g} \mathrm{ml}^{-1}\right)$. Filled squares, CFU counts; filled circles, MPN counts. The experiment was repeated five times with similar results. A typical experiment is shown. The standard deviation for CFU did not exceed 10 to $20 \%$ for the CFU mean and 20 to $30 \%$ for the MPN mean. b The quantity of total mRNA ( $M$ values) in the DE, DM, and DL cultures to that in the Log cultures (after normalization to $16 \mathrm{~S}$ rRNA)

\section{The total level of mRNA significantly decreases in dormant cells}

Transcriptional profiling of different $M$. tuberculosis populations was performed by RNA-seq. $\mathrm{K}^{+}$-deficient cultures at the logarithmic growth phase (Log) were compared with early dormant (DE), and rifampicintreated 'zero-CFU' middle dormant (DM) and late dormant (DL) mycobacteria to determine the changes accompanying $\mathrm{K}^{+}$-deficiency, transition to dormancy, and prolonged persistence of dormant NC cells, respectively (Fig. 1a). Three independent replicates allowed estimating biological variability and identifying differentially expressed genes. After sequencing, we mapped the reads to $M$. tuberculosis $\mathrm{H} 37 \mathrm{Rv}$ genome, and calculated mapping statistics (Additional file 1: Table S1). The percentages of non-rRNA reads mapped to different annotated features are shown in Table 1. We noted that markedly lower proportion of reads were mapped to protein-coding genes in DM and DL cultures in comparison with $\mathrm{DE} \quad(t$-test $p$-values $<0.01$ for both

Table 1 Mapping statistics

\begin{tabular}{lrrrr}
\hline & Log & DE & DM & DL \\
\hline CDS (\% non-rRNA) & 80.1 & 60.2 & 12.3 & 18.5 \\
tRNA (\% non-rRNA) & 3.3 & 1.7 & 41.5 & 13.8 \\
rrnB, 4.5S and tmRNA (\% non-rRNA) & 14.9 & 26.3 & 41.0 & 61.3 \\
Intergenic RNA (\% non-rRNA) & 1.6 & 11.8 & 5.1 & 6.4 \\
Intergenic RNA (\% sense CDS) & 2.0 & 19.7 & 41.7 & 34.7 \\
Antisense RNA (\% sense CDS) & 13.1 & 17.7 & 30.8 & 35.8 \\
\hline
\end{tabular}

The numbers in the rows one to four represent the percentage of non-rRNA reads mapped to the indicated RNA types for each of the four $M$. tuberculosis states. The percentage of reads mapped to intergenic and antisense RNA to the reads mapped to coding sequences (CDS) in sense orientation are shown in the fifth and sixth rows comparisons), suggesting a significant decrease of transcriptional activity in 'zero-CFU' $M$. tuberculosis cells. Therefore, to obtain unbiased RPKM values, we normalized the number of reads mapped to a protein-coding gene to the number of reads mapped to all proteincoding and non-coding RNA genes, excluding reads mapped to rRNA, and tRNA genes. RPKM values were not calculated for duplicated genes or instances, where less than five reads were mapped to a gene (Additional file 2: Table S2). To compare correlation within and between replicates, we selected the genes with assigned RPKM values for all samples and calculated Spearman correlation coefficients (Additional file 3: Table S3). All samples within triplicates demonstrated high correlation $(\mathrm{R}>0.85)$. Comparison between replicates showed that DM and DL cultures were very similar in their transcriptional profiles $(R>0.85)$ and might even be considered to represent the same biological sample, indicating that the protein-coding transcriptome of dormant $M$. tuberculosis did not significantly change after prolonged persistence. Interestingly, DE and DM cultures showed slightly higher correlation $(R=0.81)$ than Log and $D E$ cultures $(R=0.75)$. The difference between correlation coefficients was statistically significant (Steiger's Z-test, $p<0.01$ ) [27]. Therefore, the transition of mycobacteria to early dormancy (when about $90 \% M$. tuberculosis became NC; Fig. 1a) induced more pronounced changes in the transcriptome than the conversion of the remaining $10 \%$ of dividing mycobacteria in population to $\mathrm{NC}$ state and formation of 'zero-CFU' culture, which is consistent with quantitative assessment of the population structure.

Our RNA-seq mapping statistics suggested that the total level of mRNA significantly decreased in DM and 
DL transcriptomes. The change of mRNA content per cell may result from: (i) the change of the total quantity of RNA per cell, and (ii) the change of proportion of mRNA in the transcriptome. To estimate the first component, we normalized the quantity of RNA isolated from Log and DM cells to the quantity of DNA isolated from these cells. The quantity of DNA proved to be a robust parameter for estimation of the number of cells for mycobacteria [28]. In slow-growing mycobacteria, the quantity of DNA per cell seems to be relatively constant at different growth rates: M. bovis BCG was predicted to contain $6.73 \mathrm{fg}$ of DNA per cell at a doubling time $23.1 \mathrm{~h}^{-1}$ and $5.35 \mathrm{fg}$ of DNA per cell at a doubling time $69.3 \mathrm{~h}^{-1}$ [29]. Therefore, we may assume that in our model the quantity of DNA per cell remained constant. Our results showed that RNA/ DNA ratio in Log cells $(0.17 \pm 0.03, n=3)$ was almost equal to RNA/DNA ratio in DM cells, cultivated under rifampicin $(0.14 \pm 0.03, n=3)$. These data suggested that the quantity of RNA per cell remained constant at different time points in our model.

To estimate the change of proportion of mRNA in the transcriptome we normalized the quantity of total mRNA to the quantity of $16 \mathrm{~S}$ ribosomal RNA. The total mRNA pool represents a minor proportion (approximately $2 \%$ ) of the transcriptome in bacteria [30]. The proportion of mRNA of a certain gene in the transcriptome $(Q)$ is composed of (a) the proportion of total mRNA in the transcriptome (mRNA) and (b) the proportion of this mRNA molecule in total mRNA pool, which may be represented by RPKM value. Therefore, if we compare samples $A$ and $B$, the change of proportion of individual mRNA in total transcriptome $\left(Q_{B} / Q_{A}\right)$ may be represented as:

$$
\frac{Q_{B}}{Q_{A}}=\frac{m R N A_{B} \times R P K M_{B}}{m R N A_{A} \times R P K M_{A}}
$$

To measure the change of proportion of individual mRNA in total transcriptome $\left(Q_{B} / Q_{A}\right)$ we employed qRT-PCR with $16 \mathrm{~S}$ rRNA as a reference gene. Ribosomal RNAs constitute a dominant fraction (more than $80 \%$ ) of the total RNA in bacterial cells [30] and rRNA levels are considered to be relatively constant at most growth rates [31]. Therefore, in the condition of decreased mRNA content, 16S rRNA is an appropriate reference gene to calculate the quantity of individual mRNAs in total transcriptome.

To represent the ratio of total mRNA in sample B to that in sample A we introduced the value $M_{B / A}$ :

$$
M_{B / A}=\frac{m R N A_{B}}{m R N A_{A}}=q P C R_{B / A}^{16 S} \times \frac{R P K M_{A}}{R P K M_{B}}
$$

We chose 12 genes and measured changes of their expression in samples DE, DM and DL relative to Log by
qRT-PCR, using 16S rRNA gene as a reference (Additional file 4: Table S4). As we were unable to obtain PCR products for the genes with low RPKM values in DM and DL samples, highly expressed (overrepresented) genes were chosen for the analysis. Spearman correlation coefficients between changes of expression measured by RPKM and qPCR were: 0.84 (DE vs. $\log$ ), 0.87 (DM vs. $\log$ ), and 0.88 (DL vs. Log). On the basis of qPCR data and RPKM for 12 selected genes we calculated $M$-values for samples DE, DM and DL relative to Log (Fig. 1b). According to average $\mathrm{M}$-values, the quantity of mRNA relative to $16 \mathrm{~S}$ rRNA was maximal in Log, slightly decreased in DE, and significantly decreased (30-50-fold) in DM and DL cultures.

\section{Differential expression of protein-coding genes on dormancy}

Despite significant transcriptional repression in DM and DL cultures, the expression of protein-coding genes in these samples could be assessed by RNA-seq. To find differentially expressed genes we used edgeR software [32] (Additional file 5: Table S5). This algorithm does not rely on RPKM. Therefore, there are differences between fold changes calculated with edgeR and by direct comparison of RPKM values. We performed pair-wise comparisons between Log and DE transcriptomes (adaptation to $\mathrm{K}^{+}$-deficiency and the early stages of dormancy), DE and DM transcriptomes (formation of the 'zero-CFU' phenotype), and DM and DL transcriptomes (prolonged persistence of 'zero-CFU' cells).

After calculating differential expression values, we normalized them to the quantity of total mRNA using Mvalues (Additional file 5: Table S5). We noted, however, that there were no protein-coding genes, whose absolute expression level increased or remained at the same level in DM or DL relative to DE. Additionally, earlier we noted that transcriptional profiles in DM and DL were quite similar to that in $\mathrm{DE}$, suggesting that despite significant downregulation, the relative representation of transcripts in mRNA pool did not show dramatic changes. This prompted us to examine differential expression using non-normalized expression values. In this case, we measured changes of relative representation of individual transcripts in the total mRNA pool, but not the absolute quantities of the transcripts in cells. To facilitate the search for meaningful changes in gene expression, we implemented gene set enrichment analysis using functional categories from TubercuList and PATRIC databases [33, 34]. For this analysis, we chose the genes that showed more than two-fold statistically significant up- or downregulation. The results of functional enrichment analysis are shown in Additional file 6: Table S6. 


\section{Comparison of Log and DE cultures}

$\mathrm{K}^{+}$-deficient conditions reduced the levels of transcripts encoding NADH dehydrogenase complex I (nиоA-N) and succinate dehydrogenase complex (sdhABCD), whereas the genes encoding two copies of NADHdehydrogenase complex II were either significantly upregulated (ndh) or unchanged (ndhA) (Fig. 2a). We also observed a significant downregulation of expression of the components of the cytochrome $c$ pathway in the electron transport chain such as $b c 1$ complex $(q c r C A B)$ and $a a_{3}$-type cytochrome $c$ oxidase $(\operatorname{ctaBCDE})$. In contrast, the genes encoding cytochrome bd (cydABCD) were expressed at the same level. The genes encoding the components of FOF1 ATP-synthase were also downregulated during cultivation in $\mathrm{K}^{+}$-deficient media. Other groups of genes that showed significant downregulation were those encoding transport complexes Mce1 and Mce4, and proteins implicated in phosphate transport. PE-PGRS genes showed dramatic changes: among 62 genes, 51 showed statistically significant upregulation in DE cells, and most of them remained upregulated in DM and DL cells, where PE-PGRS 5, 10, 14, 15, 25, and 41 were expressed at relatively high levels.

\section{Comparison of DE and DM cultures}

After formation of mycobacteria with 'zero-CFU' phenotype (DM cultures), the expression of genes encoding enzymes of the tricarboxylic acid cycle, glyoxylate and methylmalonate pathways was significantly repressed (Fig. 2b). This tendency was already detected in DE cultures and became more pronounced DM and DL. In contrast, icl1 encoding isocitratelyase and mutAB encoding methylmalonyl-CoA mutase, the key enzymes of glyoxylate and methylmalonyl pathways, respectively, were upregulated in DE mycobacteria and remained upregulated in DM and DL cultures. The genes encoding ribosomal proteins and $m m p L 8$ gene cluster were significantly downregulated in DM and DL cells.

The only group of genes that showed statistically significant upregulation was the group of genes encoding vitamin B12-synthesizing enzymes including cobalamin biosynthetic operon cobJHKLM.

\section{Comparison of DM and DL cultures}

As shown above, both DM and DL mycobacteria were characterized by equally low RNA content and similar transcriptional profiles. Nevertheless, we were able to identify 293 genes with more than two-fold statistically significant up- and downregulation (Additional file 5: Table S5). mmpL10 gene cluster was significantly downregulated in DL relative to DE (Fig. 2b). Surprisingly, some genes involved in the biosynthetic processes, including $\mathrm{ribD}$ (riboflavin biosynthesis), cysO (cysteine biosynthesis), grcC2 (polyprenyl diphosphate synthase), and $p c k A$ (iron-regulated phosphoenolpyruvate carboxykinase, a rate-limiting gluconeogenic enzyme) were upregulated in persisting NC M. tuberculosis. The transcripts of several genes involved in lipid and fatty acid metabolism such as $\operatorname{des} A 2$ and $\operatorname{des} A 3$ (desaturases), fadE23 and fadE24 (acyl CoA dehydrogenase, lipid degradation), ech14 (enoyl CoA hydratase), fabD (malonyl CoA hydratase), hsaE (lipid degradation), and pks10 (chalcone synthase) were also upregulated during the transition from the middle dormant (DM) to late dormant (DL) state.

We also found that several genes involved in the expression and function of ribosomal proteins, including rpmJ and rpmI, rpsQ and $r p s M, r p l K$ and $r b f A$ (ribosome-binding factors), greA (transcriptional elongation factor), sigL and $r s b W$ (anti-sigma factors) were upregulated on late dormancy. The genes involved in cell adaptation and repair, including those coding for chaperons, heat shock proteins, and toxin-antitoxin (TA) modules, were also found to be markedly overrepresented on late dormancy: $m s r B$ (peptide methionine sulfoxide reductase), serB1 (phosphoserine phosphatase), hsp (heat shock protein), $h t p X$ (peptidase involved in adaptation), $\operatorname{clp} B$ (ATP-dependent endopeptidase), pip (proline release from short peptides), vapBC10, and vapBC20 (TA modules). The genes involved in detoxification reactions such as cyp132 and cyp130, and protein degradation such as $g c v B$ (glycine dehydrogenase) and mpa (proteasome) also demonstrated upregulation in DL versus DM cells.

\section{Non-coding transcriptome}

Recent studies have identified multiple non-coding RNAs (ncRNAs) in M. tuberculosis [35-40]. According to our mapping statistics (Table 1), the quantity of intergenic transcripts (including small RNAs, $5^{\prime}$ and $3^{\prime}$ UTRs) and the relative quantity of antisense RNAs to protein-coding transcripts increased in dormant $M$. tuberculosis, suggesting that ncRNA molecules are upregulated relative to protein-coding transcripts.

By visual inspection of transcriptional profiles, we identified 37 candidate ncRNA molecules, including 8 intergenic small RNAs and 29 antisense RNAs (Additional file 7: Table S7). All intergenic small RNAs and two antisense RNAs have been previously reported [35-38].

According to RPKM values several ncRNAs demonstrated increased expression in dormant cells (Additional file 7: Table S7): ncRv0539c (antisense to putative dolichyl-phosphate sugar synthase) was 10 times upregulated in DE cells; ncRv1162c (antisense to narH) was 20 times upregulated in $\mathrm{DE}$ cells followed by moderate downregulation in DM and DL cells; ncRv12659 (the transcript originating within a prophage) [41] was 6 
A NADH and succinate-
dehydrogenase complexes

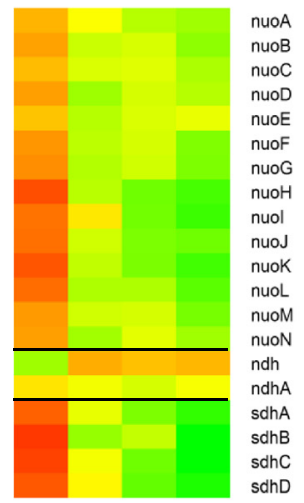

Cytochromes $b d, b c 1$ and cytochrome $\mathrm{C}$ oxidase

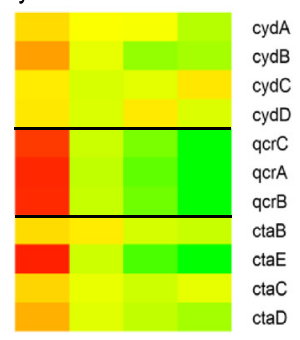

F0F1 ATP-synthase

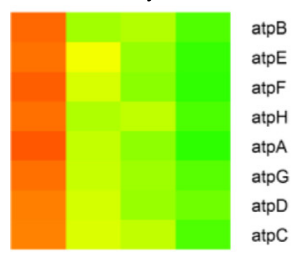

Transport complexes Mce1 and Mce4

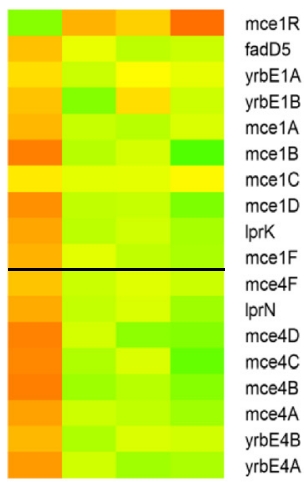

题㟔 $\Sigma_{0} \overrightarrow{0}$
PE-PGRS proteins

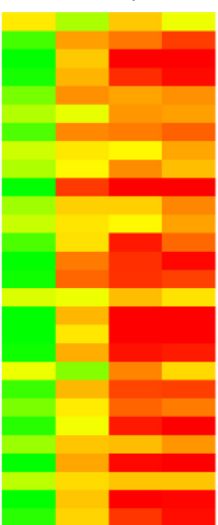

PE_PGRS1 PE-PGRS2
PE PGRS3 PE-PGRS4
PE PGRSS PEE-PGRS
PE-PRSG PE-PGRS7 PEE PGRSB
PE PGRSO PE-PGRS9
PEE-PGRS10 PE-PRRS10 PEE-PRRS11
PE - PGRSS12

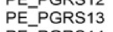
PE-PSRS14 $P E-P G R S 15$
$P E$ PE-PGRS16
PE
PEGRS17 PE-PGRS17
PE PGRS18

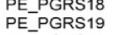
PE-PGRS20 PE-PGRS21 PE-PGRS22 PE -PFRS23 PE-PGRS24
PE PGPS25

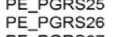
1
$P E-P G R S 27$ PE_PGRS28 PE-PGRS29 PE_PGRS31 PE_PGRS32 PE_PGRS33
PE_PGRS34 PE PGRS35 PE_PGRS37 PE_PGRS38 PE_PGRS39 PE_PGRS40 PE_PGRS42 PE_PGRS 43 PE_PGRS44 PE-PPRS45

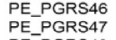

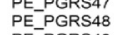
PEEPRSS49 PE_PGRS50 PE_PGRS51 PE_PGRS52 PE_PGRS53 PE_PGRS54 PE_PGRS55 PE_PGRS57 PE_PGRS58 PE_PGRS59 PE_PGRS60

\section{Phosphate transport}

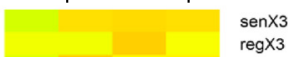

regX3

ppx1

Rv0818

phoT
phoY2

pstS3

pstS3

pstC2

pstA1

pstS2
pstB
pstS1

pstC1

pstA2

Rv1026

ppk1

Toxin-antitoxin loci

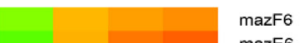

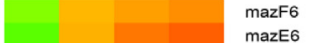

mazE7

mazF7

vapC10

vapB10

vapC20

vapB20

vapC23

vapB23
vapC34

vapB34

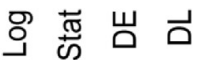

B

TCA cycle, glyoxylate and methylmalonate pathways

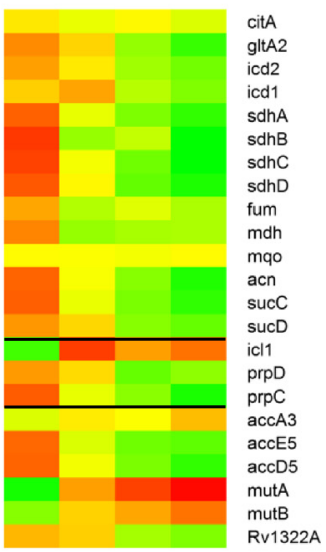

\section{B12 biosynthesis}

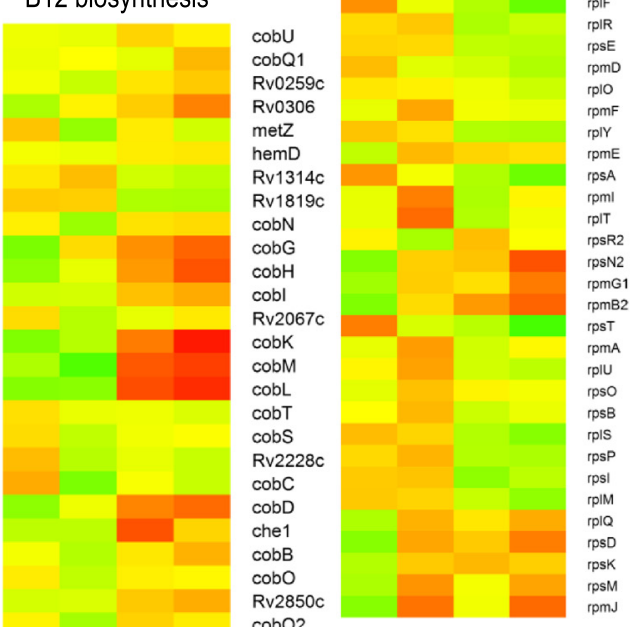

Transport system Mmpl8 Transport system Mmpl10
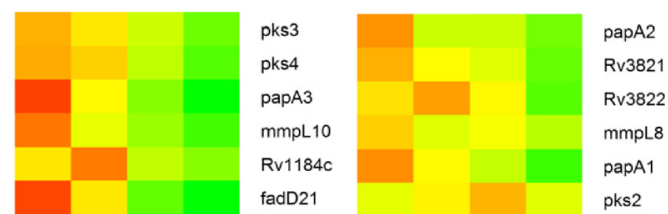

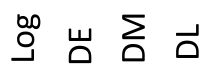

骂

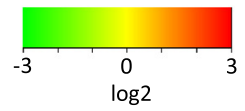

Ribosomal proteins

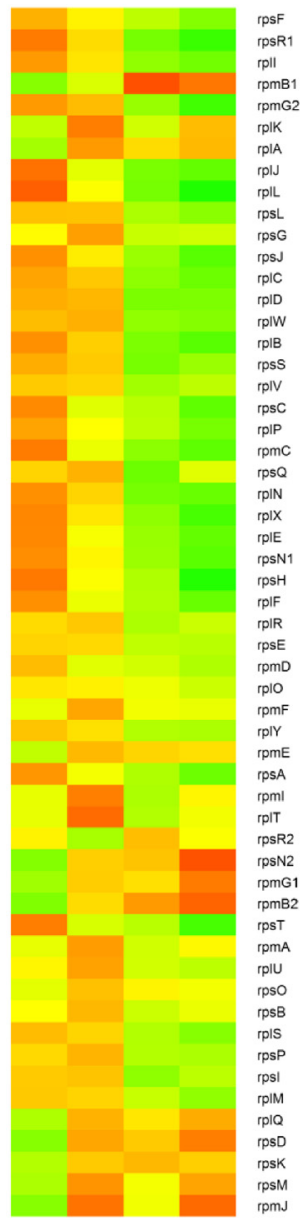

PSSF
PSSP1 pmB1

rpmG2

rpla
rols

psL.

ips J

to

Plis

ipsc

pmc

$\min$

iple

E

.

ME

2

A

o

(1)

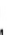

.

.


(See figure on previous page.)

Fig. 2 Red-green display summarizing regulation of the selected genes. Gene expression ratios were determined using the edgeR package, log2 transformed, normalized to the average level across the samples and displayed according to the color code. Gene groups were retrieved from the PATRIC database and modified. a The groups of genes with differential representation in the Log and DE samples. $\mathbf{b}$ The groups of genes with differential representation in the DE and DM samples, and DM and DL samples

times upregulated in $\mathrm{DE}$ and further increased in DM and DL cells.

Since small intergenic RNAs MTS0997, MTS1338, and MTS2823 were found to be most abundant in dormant NC mycobacteria (Additional file 7: Table S7), we analyzed their expression at different dormancy stages using qRT-PCR (Fig. 3). Expression of MTS0997 remained constant in DE, but was significantly decreased in DM and DL cells. MTS2823 demonstrated significant accumulation in DE cultures, whereas MTS1338 level remained constant throughout the dormancy, in contrast to the general transcriptional repression in dormant $M$. tuberculosis. Thus, the dormant transcriptome of mycobacteria was proved to be enriched in ncRNAs.

\section{Overexpression of $M$. tuberculosis non-coding RNAs affects the growth rate}

Next, we examined functional roles of small RNAs in $M$. tuberculosis. Two highly expressed small RNA molecules MTS0997 and MTS1338 were cloned in the plasmid vector under the control of the strong $r r n B$ promoter of M. smegmatis and transformed into $M$. tuberculosis cells. The overexpression of both MTS0997 and MTS1338 in M. tuberculosis resulted in slow bacterial growth in liquid medium (Fig. 4) with more pronounced phenotype for MTS1338.

\section{Cleavage of 23S rRNA is a hallmark of dormant cells}

The examination of total RNA quality by gel electrophoresis revealed the fragmentation of $23 \mathrm{~S}$ rRNA in DE,

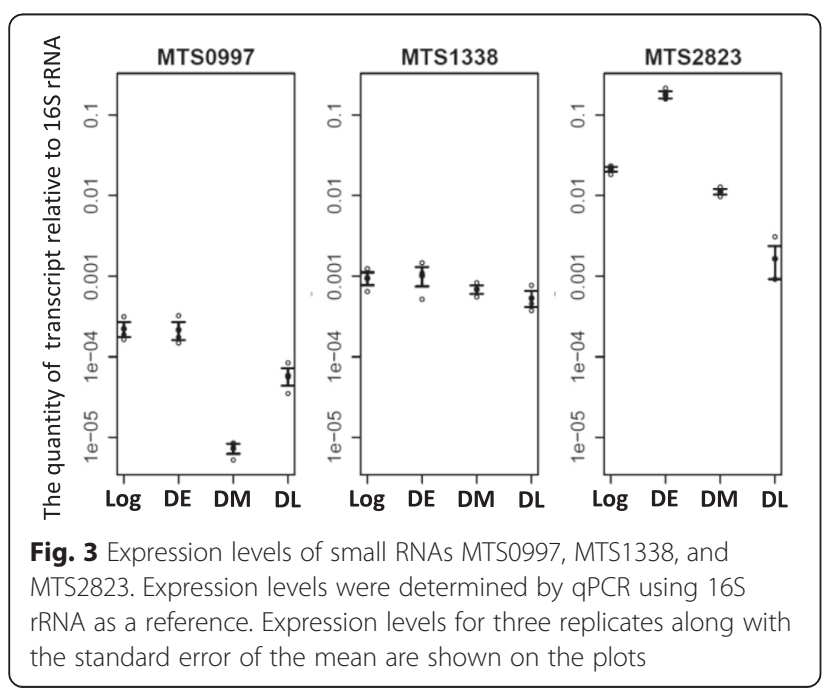

DM, and DL cultures (Fig. 5a). Northern blot analysis showed that the major cleavage point was located approximately $600 \mathrm{nt}$ from the $5^{\prime}$ end of $23 \mathrm{~S}$ rRNA. Almost half of the 23S rRNA molecules in DM bacteria were cleaved (Fig. 5b). The primer extension assay was used to map the exact position of the cleavage site between residues G592 and A593. The cleavage occurred in DE cultures, i.e., during the initial phase of dormancy, and became more pronounced in DM and DL mycobacteria (Fig. 5c). In $23 \mathrm{~S}$ rRNA, the cleavage site is located in a single-strand region near helix 24 of domain I (Fig. 5d); however, this region does not participate in the catalytic activity of ribosomes. Therefore, the role of site-specific $23 \mathrm{~S}$ rRNA cleavage in $M$. tuberculosis dormancy remains to be elucidated.

\section{Discussion}

To perform transcriptional profiling of dormant $\mathrm{NC}$ cells by RNA-seq, we employed a previously developed model of non-culturability in $\mathrm{K}^{+}$-deficient medium, which has been earlier used for transcriptome analysis of dormant versus dividing mycobacteria by microarray [20]. However, in the previous study we used a heterogeneous population containing, along with NC cells, a minor subset of dividing cells $\left(1 \times 10^{3}-10^{4}\right.$ cells $\left.\mathrm{ml}^{-1}\right)$. The addition of a moderate concentration of rifampicin

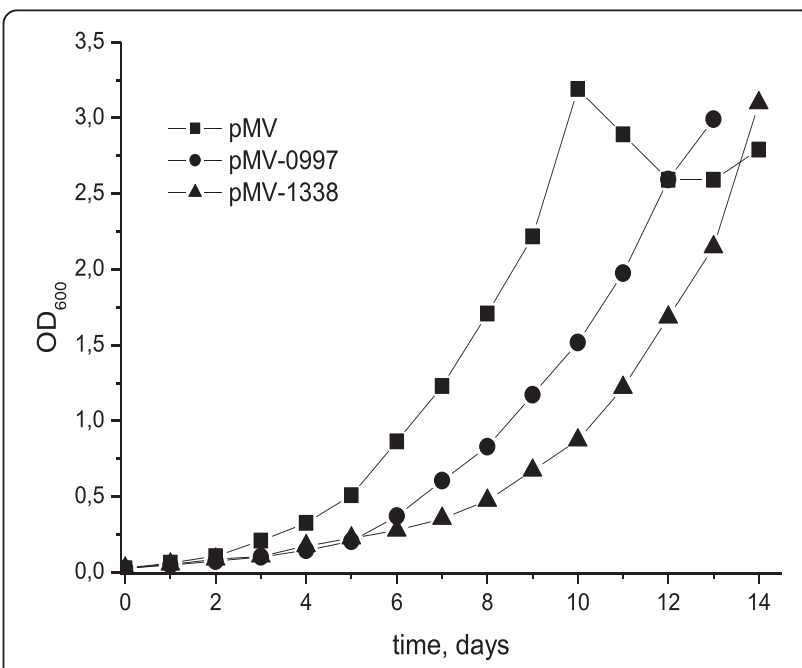

Fig. 4 Growth curves of M. tuberculosis overexpressing MTS0997 and MTS1338. Mycobacteria were cultured in Sauton medium supplemented with ADC and Tween- 80 at $37^{\circ} \mathrm{C}$ with agitation (200 rpm); M. tuberculosis transformed with the empty pMV261 vector was used as negative control 

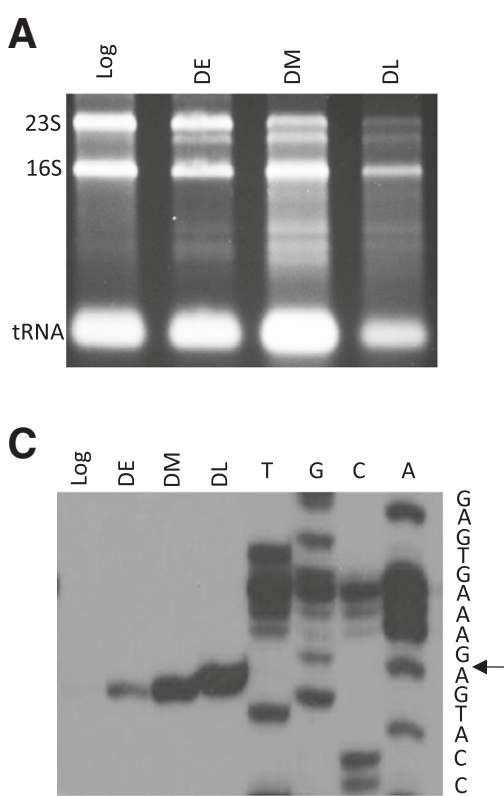
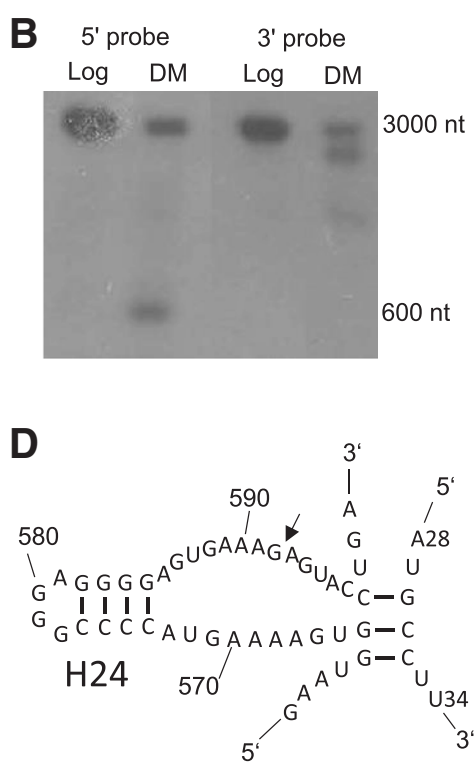

Fig. 5 Cleavage of $23 \mathrm{~S}$ rRNA. a Non-denaturing agarose gel electrophoresis of total RNA isolated from the Log, DE, DM, and DL M. tuberculosis cultures. b Northern blotting with the probes complementary to $5^{\prime}$ and $3^{\prime}$ ends of $23 S$ rRNA from the Log and DM cells. c Primer extension analysis with the primer PE_667 complementary to 23S rRNA. RNA was isolated from the Log, DE, DM, and DL cells. The cloned 235 rDNA fragment was also analyzed by Sanger sequencing with PE_667. The arrow indicates the cleavage site. $\mathbf{d}$ The structure of helix 24 and the adjacent region of $M$. tuberculosis 235 rRNA. The cleavage site is indicated by the arrow. The structure was adopted from www.rna.icmb.utexas.edu [78] and modified

allowed to eliminate this subset of metabolically active mycobacteria [25] and to obtain a homogenous population of dormant cells with the 'zero-CFU' phenotype.

In the present study, we demonstrated a significant decrease in total mRNA content in dormant M. tuberculosis (especially after establishing 'zero-CFU' state in DM and DL cultures), which indicates global repression of all protein-coding genes on dormancy. The problem of comparing gene expression levels in samples with different mRNA content has been recently addressed for eukaryotic cells. Aanes et al. proposed an approach that uses experimentally measured polyA ${ }^{+}$RNA amounts as scales to normalize expression levels in different samples [42]. Another strategy employed RNA spike-in controls in quantities proportional to the number of cells and estimated scaling factors based on local regression (LOESS) [43].

In this study, we employed a two-step approach: firstly, we calculated RNA to DNA ratio as a measure of total RNA content per cell in compared samples. Secondly, we normalized the quantity of total mRNA to the quantity of $16 \mathrm{~S}$ ribosomal RNA in compared samples. Our results suggested that the quantity of RNA per cell was equal at different points in our model. However, dormant cells DM and DL with the 'zero-CFU' phenotype experienced 30-50 fold downregulation of total mRNA. The downregulation of transcription was so dramatic that there were no genes, whose expression was upregulated in absolute values. Therefore, we performed differential expression analysis in terms of relative representation of particular transcripts in the whole mRNA pool, and not their absolute quantities per cell.

The observed global transcriptional repression of protein-coding genes may be a strategy to maintain dormancy by arresting cell metabolic activity. What is the nature of mRNAs detected in NC cells? It is known that under normal conditions, individual transcripts in bacterial cells have a very short lifetime [44-46], and the presence of mRNA in NC mycobacteria in the absence of RNA synthesis appeared rather unexpected. $\mathrm{Hu}$ et al. were the first to demonstrate the preservation of several individual mRNA molecules in rifampicin-treated $M$. tuberculosis cells using RT-PCR; however, global transcriptome was not analyzed [13]. A recent study has shown a significant increase in the average mRNA halflife in $M$. tuberculosis with the decrease in cultivation temperature and under hypoxic conditions [47]. In our model of non-culturable $M$. tuberculosis, we observed a dramatic decrease in transcriptional activity for dormant mycobacteria as indicated by the rate of uracil incorporation [25]. However, we found that dormant NC cells are characterized by the low-abundance but stable transcriptome for at least 10 days of persistence in the 'zero-CFU' state. The population of stable individual transcripts in dormant $M$. tuberculosis probably represents 
mRNA molecules synthesized in the early stages of $\mathrm{K}^{+}$-deficiency and stabilized in the $\mathrm{NC}$ state, when de novo RNA synthesis is evidently blocked.

The analysis of persisting transcripts with significantly increased ( $\geq 2$-fold) relative representation in the late dormancy revealed a cohort of mRNA molecules coding for biosynthetic enzymes, proteins involved in adaptation and repair processes, detoxification, and control of transcription initiation. Although active metabolic reactions are suppressed in dormant NC $M$. tuberculosis with the 'zero-CFU' phenotype, this cohort of stable mRNA molecules could represent a pool of readily activable transcripts preserved for the initial stage of resuscitation as it has been suggested for mRNA found in Bacillus subtilis spores [48].

The most prominent feature of the transcriptome from M. tuberculosis with 'zero-CFU' phenotype was downregulation of the genes encoding ribosomal proteins (Fig. 2b). A similar transcriptional signature has previously been observed during starvation [12], stationary phase, in the Wayne model [49], and in persistent mycobacteria after antibiotic treatment [50]. In our model, the decrease in transcripts encoding ribosomal proteins occurred only after the transition to 'zero-CFU' state and not as an early response to $\mathrm{K}^{+}$-deficiency, which may represent a specific feature of $M$. tuberculosis adaptation to prolonged dormancy, when only the cells not expressing ribosomal proteins could survive.

A striking feature of the NC transcriptome is a significant proportion of small ncRNAs. Recently, multiple ncRNA molecules were discovered in $M$. tuberculosis $[35-37,39,51,52]$, where they are thought to participate in the regulation of general stress responses [36, 53, 54]. However, the investigation of the roles of small ncRNAs in $M$. tuberculosis has just started [35, 41, 55]. In the present study, two small RNA molecules MTS0997 and MTS1338 were found to be very abundant in NC mycobacteria characterized by the 'zero-CFU' phenotype. Both MTS0997 and MTS1338 have been identified earlier in M. tuberculosis and M. bovis [36, 37, 56]. It has been shown that these small RNAs are induced in the stationary phase of mycobacterial cultures [35], which is consistent with our results demonstrating that MTS0997 and MTS1338 overexpression resulted in growth inhibition (Fig. 4), suggesting the role of these small RNAs in the transition to dormancy and maintenance of the NC status. Arnvig et al. have demonstrated that overexpression of another small RNA, MTS2823, also resulted in slow growth of $M$. tuberculosis [36]. Interestingly, MTS0997 is considered to be involved in cAMPdependent regulatory processes. Expression of this small RNA is dependent on the synthesis of adenylate cyclase (Rv1264) and cAMP levels [56]. We have recently demonstrated that intracellular cAMP levels regulate the early stages of $M$. smegmatis resuscitation from the dormant NC state [57]. Cumulatively, these data suggest that MTS0997 may be involved in the control of cAMP production in $M$. tuberculosis and thus may participate in the transition to a slow-metabolism state and in the formation of the NC phenotype, when abundant MTS0997 expression would arrest NC cell growth until conditions are appropriate for resuscitation.

Another feature of dormant $M$. tuberculosis was the cleavage of 23S rRNA between residues G592 and A593. Generally, rRNA cleavage by endoribonucleases initiates its degradation during stress conditions, leading to the accumulation of small rRNA fragments for further degradation to mononucleotides by exoribonucleases $[58,59]$. If uncontrolled, this process is detrimental and may lead to cell death $[60,61]$. During hypoxia, mycobacteria stabilize their ribosomes by keeping $30 \mathrm{~S}$ and $50 \mathrm{~S}$ ribosomal subunits in the associated form; the inability to stabilize ribosomes results in their degradation and loss of cell viability [61]. In our model, rRNA remained fragmented but not completely degraded even after prolonged persistence in the NC state. The cleavage site is located in a singlestrand region near helix 24 of domain I, which could interact with ribosomal proteins L22 and L24 [62]. The analysis of $E$. coli ribosome crystal structure (PDB ID $2 \mathrm{QBE}$ ) has shown that the region around the cleavage site is surface-exposed [63] and thus would be readily accessible for proteases.

Ribosomal RNA cleavage may be due to the activity of the toxin-antitoxin (TA) systems of M. tuberculosis $[11,64]$. Thus, it has been shown that mycobacterial toxin MazF-mt6 can disable protein synthesis by cleaving $23 \mathrm{~S}$ rRNA at a functionally essential region located in ribosomal A site [65] and that toxin VapC20 can inhibit translation by the cleavage of the Sarcin-Ricin loop in $23 \mathrm{~S}$ rRNA [66]. In our model, several TA modules such as mazEF6, mazEF7, VapBC10, VapBC20, $\operatorname{Vap} B C 23$, and $V a p B C 34$ demonstrated significant upregulation in dormant cells (Fig. 2a).

Despite significant upregulation of mazEF6 and vapBC20 TA loci, we did not observe cleavage of $23 \mathrm{~S}$ rRNA at the cleavage sites specific for these toxins. Indeed, activity of TA systems is mainly regulated at posttranscriptional level: degradation of antitoxin proteins induces activity of toxins [67]. Therefore, transcriptional upregulation does not necessarily indicate activation of TA modules.

\section{Conclusions}

Transcriptomic profiling of dormant NC M. tuberculosis by RNA-seq revealed, for the first time, a global transcriptional repression of protein coding genes. The analysis of residual low-abundant transcripts displayed a cohort of mRNA molecules coding for biosynthetic 
enzymes, proteins involved in adaptation and repair processes, detoxification, and control of transcription initiation. A remarkable transcriptome stability of longpersisting dormant mycobacteria found in this study suggests effective adaptation mechanisms underlying readiness of $\mathrm{NC}$ mycobacteria to resuscitation. The mRNAs in dormant cells may represent a pool of stable transcripts, which are rapidly translated upon resuscitation from dormancy. The cleavage of $23 \mathrm{~S}$ rRNA at a specific point and the abundance of several small ncRNAs in NC M. tuberculosis may indicate their significance for the maintenance of dormancy and suggest the molecular basis of LTB infection.

\section{Methods}

\section{Bacteria and media}

Dormant non-culturable $M$. tuberculosis was obtained as described previously [20]. Briefly, M. tuberculosis strain $\mathrm{H} 37 \mathrm{Rv}$ was initially grown from frozen stocks for 10 days in Sauton medium containing (per liter): $0.5 \mathrm{~g} \mathrm{KH}_{2} \mathrm{PO}_{4}$, $1.4 \mathrm{~g} \mathrm{MgSO}_{4} \cdot 7 \mathrm{H}_{2} \mathrm{O}, 4 \mathrm{~g} \mathrm{~L}$-asparagine, $60 \mathrm{ml}$ glycerol, $0.05 \mathrm{~g}$ ferric ammonium citrate, $2 \mathrm{~g}$ sodium citrate, $0.1 \mathrm{ml} 1 \% \mathrm{ZnSO}_{4} \cdot 7 \mathrm{H}_{2} \mathrm{O}$, pH 7.0 (adjusted with $1 \mathrm{M}$ $\mathrm{NaOH}$ ) and supplemented with albumin, glucose and $\mathrm{NaCl}$ (ADC) [68] and $0.05 \%$ Tween 80 , at $37{ }^{\circ} \mathrm{C}$ with agitation $(200 \mathrm{rpm})$. The starter culture was inoculated into fresh medium (same composition) and incubated for another 10 days until its optical density at $600 \mathrm{~nm}$ $\left(\mathrm{OD}_{600}\right)$ reached 4.0. These bacteria were then inoculated $\left(5 \times 10^{5}\right.$ cells $\left.\mathrm{ml}^{-1}\right)$ into $\mathrm{K}^{+}$-deficient Sauton medium (containing $8.9 \mathrm{~g} \mathrm{Na}_{2} \mathrm{HPO}_{4} \cdot 12 \mathrm{H}_{2} \mathrm{O}$ instead of $0.5 \mathrm{~g}$ $\left.\mathrm{KH}_{2} \mathrm{PO}_{4}\right)$ and grown at $37{ }^{\circ} \mathrm{C}, 200 \mathrm{rpm}$. After 14-15 days of culture, when CFU started to decrease, rifampicin $\left(5 \mu \mathrm{g} \mathrm{ml}^{-1}\right)$ was added to eliminate culturable bacteria and to obtain the NC population with the 'zero-CFU' phenotype.

\section{Cell viability estimation}

To assess cell viability, 10-fold serial dilutions of $M$. tuberculosis cultures were plated in triplicate onto solidified Sauton agar supplemented with ADC and incubated at $37{ }^{\circ} \mathrm{C}$ for 25 days, after which colonyforming units (CFUs) were counted. To assess the proportion of bacteria with the ability to resuscitate in liquid medium by most probable numbers (MPN) assay, 10-fold bacterial dilutions were resuspended in ADC-supplemented Sauton medium diluted 1:1 (v/v; final glycerol concentration, $0.6 \%$ ) [18] and seeded into 48-well Corning microplates, which were incubated statically at $37{ }^{\circ} \mathrm{C}$ for 30 days. The wells with visible bacterial growth were counted as positive, and MPN values were calculated using standard statistical methods [69].

\section{Isolation of RNA and DNA, Illumina sequencing}

RNA was isolated from $M$. tuberculosis cultures at various time points during initial growth in $\mathrm{K}^{+}$-deficient medium and after addition of rifampicin: cells at the logarithmic phase after 4 days in $\mathrm{K}^{+}$-deficient medium (Log); early dormant cells at the stationary phase after14 days in $\mathrm{K}^{+}$-deficient medium (DE); middle dormant cells ('zero-CFU' phenotype) 10 days after the addition of rifampicin (DM); and late dormant cells ('zero-CFU' phenotype) 20 days after the addition of rifampicin (DL). Each time point was represented by three independently grown cultures. Bacterial cultures were rapidly cooled on ice, centrifuged, and total RNA was isolated by phenol-chloroform extraction and cell disruption with BeadBeater (BioSpec Products, Bartlesville, OK, USA) as previously described [70]. DNA was isolated from triplicates of Log and DM cultures as described previously [71]. After isolation, RNA was treated with Turbo DNase (Life Technologies, Carlsbad, CA, USA) to remove traces of genomic DNA, and purified with the RNeasy mini kit (Qiagen, Venlo, Netherlands). RNA preparations were depleted of $16 \mathrm{~S}$ and $23 \mathrm{~S}$ rRNA using the MicrobExpress kit (Life Technologies) (samples Log 1-3, DM 1-3, and DE 1) or Ribo-Zero (Epicentre, Madison, WI, USA) (samples DE 2, 3 and DL 1-3). cDNA for Illumina sequencing was prepared according to the Directional mRNA-seq Sample Preparation guide (Part \# 15018460 Rev. A) as previously described [72]. This procedure preserves strand specificity by ligation of a single-stranded 3' RNA adapter and 5' DNA adapter. Sequencing was performed by running 77 cycles on HiSeq 2000 sequencer (Illumina, San Diego, CA, USA).

\section{Processing of RNA-seq data}

The reads were aligned to $M$. tuberculosis reference sequence H37Rv (GenBank accession number AL123456.3) with Bowtie 2 [73] setting parameters $-q$-local; gene annotations were also retrieved from AL123456.3. Reads mapped to several different loci were discarded. Mapping statistics and reads per Kb per million (RPKM) values [74] for annotated genes were calculated using custom Perl scripts. Reads overlapping a gene by at least one nucleotide were counted when calculating gene expression as RPKM. To calculate RPKM values we used "effective" gene length, to which the reads could be unambiguously mapped. To ascertain 'effective'gene length, 77 nucleotide sequences were simulated from the genome sequence and aligned to the sequence under the settings used for mapping RNA-seq reads. RPKM values were not calculated for duplicated genes and for genes to which less than 5 reads were mapped. Transcriptional profiles for the forward and reverse strands of the genome representing the counts of overlapping reads for every nucleotide were generated. Transcriptional profiles were visualized with the Artemis 
genome browser [75]. The differential expression analysis was conducted using the edgeR package [32], and distribution of M. tuberculosis genes to functional categories was performed based on the TubercuList and PATRIC databases [33,34]. The testing for overrepresentation of certain functional categories among differentially expressed genes was performed using the GOseq package [76]. The results of RNA-seq and tables of raw reads were deposited in the GEO database under the accession number GSE66408.

\section{Quantitative real-time PCR}

One microgram of total RNA was used for cDNA synthesis with random hexanucleotides and SuperScript III reverse transcriptase (Life Technologies). qPCR was performed using qPCRmix-HS SYBR (Evrogen, Russia) and the LightCycler 480 Real-Time PCR system (Roche, Switzerland); cycling conditions were as follows: $95^{\circ}$ for $20 \mathrm{~s}, 61^{\circ}$ for $20 \mathrm{~s}, 72^{\circ}$ for $30 \mathrm{~s}$, repeat 40 times; primers are listed in Additional file 8: Table S8.

\section{Calculation of M-values}

To calculate $M$-values, we chose 12 genes with medium and high expression levels in DM and DE cultures, and performed qRT-PCR on the RNA isolated from Log, DE, $\mathrm{DM}$, and DL cultures using 16S rRNA as a reference gene (Additional file 4: Table S4). M-values for each of the genes were calculated according to equation:

$$
M_{\text {Sample } / \text { Log }}=q P C R_{\text {Sample } / \text { Log }}^{16 S} \times\left.^{\mathrm{RPKM}_{\text {Log }}}\right|_{R P K M_{\text {Sample }}}
$$

Where Sample $=\mathrm{DE}, \mathrm{DM}$ and DL. To estimate the change of mRNA content for each of the three comparisons, the average of $M$-values for 12 genes were calculated.

\section{Northern blotting analysis}

For the detection of $23 \mathrm{~S}$ rRNA, $2 \mu \mathrm{g}$ of total RNA isolated from the Log and DM cultures was separated on a $1 \%$ denaturing agarose gel in $1 \times$ MOPS buffer and transferred to Hybond $\mathrm{N}$ membranes (Amersham, UK) by transblotting. The membranes were hybridized overnight at $42{ }^{\circ} \mathrm{C}$ in ULTRAhyb-Oligo hybridization buffer (Life Technologies) with oligonucleotides NB5 and NB3, which were 5 '-end radiolabeled (15 pmoles) using $10 \mu \mathrm{Ci}$ of $\left[\gamma^{32} \mathrm{P}\right]$-ATP and $\mathrm{T} 4$ polynucleotide kinase (Fermentas, Lithuania). After hybridization, the membranes were washed three times in $1 \times$ saline-sodium citrate buffer with $0.1 \%$ SDS, and radioactivity was detected by exposure to an X-ray film overnight.

\section{Primer extension analysis}

The oligonucleotide PE667 for mapping of the cleavage site on 23S rRNA was radiolabeled (10 pmoles) as described above. One microgram of total RNA isolated from the Log, DE, DM, and DL cultures was hybridized with 2 pmoles PE667 and reverse transcription was performed using SuperScript III reverse transcriptase (Life Technologies); the synthesized cDNA strands were separated on a $6 \%$ denaturing polyacrylamide gel. To determine 23S rRNA cleavage site, the products of Sanger sequencing were run on four adjacent lanes. The sequencing of $23 \mathrm{~S}$ rDNA was performed using the PE667 primer and Sequenase 2.0 DNA sequencing kit (Affymetrix, CA, USA), and radioactivity was detected by exposure to an $\mathrm{X}$-ray film.

\section{Plasmid construction}

Expression vectors were constructed by replacing the XbaI-HindIII fragment containing the Hsp60 promoter in pMV261 [77] with the XbaI-HindIII fragment spanning -80 to -8 bp of the $r r n B$ promoter from $M$. smegmatis. The promoter sequence was obtained by annealing oligonucleotides rrnB_F and rrnB_R (Additional file 8: Table S8). The vector was constructed so that small RNA could be inserted as a HindIII fragment downstream of the -10 region and the transcription would start at the mapped +1 nt with none or one additional nucleotide at the $5^{\prime}$ end. A synthetic transcriptional terminator was created by annealing oligonucleotides Term_F and Term_R to the insertion at the HindIII site downstream of sRNA 3' end [35]. Small RNA was amplified by PCR using primers listed in Additional file 8: Table S8. Plasmids were transferred into mycobacteria by electroporation.

\section{Availability of supporting data}

The data sets supporting the results of this article are available in the GEO data repository under the accession number GSE66408.

\section{Additional files}

Additional file 1: Table S1. Mapping statistics for each of the sequenced samples. (XLSX $9 \mathrm{~kb}$ )

Additional file 2: Table S2. RPKM values for each replicate in the corresponding cultures. (XLSX $797 \mathrm{~kb}$ )

Additional file 3: Table S3. Correlation between samples. Spearman coefficients of correlation between each of the sequenced samples are shown. (XLSX $10 \mathrm{~kb})$

Additional file 4: Table S4. Expression changes of selected genes and total mRNA transcriptome. (A) The expression of selected genes in the Log, DE, DM, and DL samples is presented as RPKM values (RNA-seq) and relative mRNA levels normalized to $16 \mathrm{~S}$ rRNA (qPCR). (B) The expression of selected genes was determined by RNA-seq (RPKM values) and $\mathrm{qPCR}$ (relative to $16 \mathrm{~S}$ rRNA) and presented as the ratio of the DE, DM, and DL values normalized to Log values. (C) Correlation between expression changes measured by RNA-seq and qRT-PCR. (D) Coefficient $M$ representing the changes in the quantity of total mRNA relative to 16S rRNA. (XLSX 15 kb)

Additional file 5: Table S5. Differential expression of protein-coding genes. The analysis of differential expression was performed with the edgeR software. Results for the following comparisons are shown: DE relative to Log, DM relative to $D E$, and $D L$ relative to $D M$. Log2 fold change of gene expression, FDR-adjusted P-value for differential expression test, and $M$-value adjusted Log2 fold change are shown for every gene in each comparison. (XLSX $683 \mathrm{~kb}$ ) 
Additional file 6: Table S6. Functional enrichments analysis. Functional enrichment analysis was performed using the GOseq package [76] and functional categories from the TubercuList and PATRIC databases [33, 34]. The lists of differentially expressed (up- and down-regulated) genes were generated by the comparison of the following samples: DE vs. Log, DM vs. DE, and DL vs. DM. For each functional category, the number of differentially expressed genes, the total number of genes in the category, and the adjusted p-value of overrepresentation are shown. (XLSX 38 kb)

Additional file 7: Table S7. Candidate non-coding RNAs. Candidate non-coding transcripts were identified by visual analysis of the transcriptional profiles and designated according to the nomenclature suggested in [79]. For each candidate non-coding RNA its type, approximate coordinates, average RPKM value in each sample, original name, and references to the studies where the transcript has been described are presented. (XLSX $13 \mathrm{~kb}$ )

Additional file 8: Table S8. Oligonucleotides used in the study. (XLSX $10 \mathrm{~kb}$ )

\section{Competing interests}

The authors declared that they have no competing interests.

\section{Authors' contributions}

ES and DI prepared cDNA samples for Illumina sequencing. DI and TS performed the general statistical analysis on the RNA-Seq data. ES, DI, TA and AK participated in interpreting the RNA-Seq results. MF and ES conducted analysis of expression of small RNAs and an experiment on overexpression of small RNAs. DI studied the cleavage of $23 \mathrm{~S}$ rRNA. ES, DI and AK wrote the manuscript. TA and AK designed the experiment and provided guidance on the whole study. All authors read and approved the final manuscript.

\section{Acknowledgements}

This work was supported by the Russian Foundation of Basic Research (grant numbers 13-04-40071-H, 13-04-40072-H, 15-04-04563 and 15-04-05286).

\section{Author details}

'Shemyakin and Ovchinnikov Institute of Bioorganic Chemistry, Russian Academy of Sciences, 117997, Miklukho-Maklaya 16/10, GSP-7, Moscow, Russian Federation. ${ }^{2}$ A.N. Bakh Institute of Biochemistry, Russian Academy of Science, 119071, Leninsky prospekt 33, Build. 2, Moscow, Russian Federation. ${ }^{3}$ Current address: The Queen's University of Belfast, School of Biological Sciences, Medical Biology Centre, 97 Lisburn Road, Belfast BT9 7BL, UK.

\section{Received: 30 March 2015 Accepted: 5 November 2015}

\section{Published online: 16 November 2015}

\section{References}

1. Zhang Y. Persistent and dormant tubercle bacilli and latent tuberculosis. Front Biosci. 2004;9:1136-56.

2. Chao MC, Rubin EJ. Letting sleeping dos lie: does dormancy play a role in tuberculosis? Annu Rev Microbiol. 2010;64:293-311.

3. Dhillon J, Lowrie DB, Mitchison DA. Mycobacterium tuberculosis from chronic murine infections that grows in liquid but not on solid medium. BMC Infect Dis. 2004:4:51

4. Khomenko AG, Golyshevskaya VI. Filtrable forms of mycobacteria tuberculosis. Z Erkr Atmungsorgane. 1984;162(2):147-54.

5. Sever JL, Youmans GP. Enumeration of viable tubercle bacilli from the organs of nonimmunized and immunized mice. Am Rev Tuberc. 1957;76(4):616-35.

6. McCune RM, Feldmann FM, Lambert HP, McDermott W. Microbial persistence. I. The capacity of tubercle bacilli to survive sterilization in mouse tissues. J Exp Med. 1966;123(3):445-68.

7. McCune Jr RM, McDermott W, Tompsett R. The fate of Mycobacterium tuberculosis in mouse tissues as determined by the microbial enumeration technique. II. The conversion of tuberculous infection to the latent state by the administration of pyrazinamide and a companion drug. J Exp Med. 1956;104(5):763-802.

8. Manabe YC, Dannenberg Jr AM, Tyagi SK, Hatem CL, Yoder M, Woolwine SC, et al. Different strains of Mycobacterium tuberculosis cause various spectrums of disease in the rabbit model of tuberculosis. Infect Immun. 2003;71(10):6004-11.
9. Karakousis PC, Yoshimatsu T, Lamichhane G, Woolwine SC, Nuermberger EL, Grosset J, et al. Dormancy phenotype displayed by extracellular Mycobacterium tuberculosis within artificial granulomas in mice. J Exp Med. 2004;200(5):647-57.

10. Wayne LG. Dynamics of submerged growth of Mycobacterium tuberculosis under aerobic and microaerophilic conditions. Am Rev Respir Dis. 1976;114(4):807-11.

11. Wayne LG, Hayes LG. An in vitro model for sequential study of shiftdown of Mycobacterium tuberculosis through two stages of nonreplicating persistence. Infect Immun. 1996;64(6):2062-9.

12. Betts JC, Lukey PT, Robb LC, McAdam RA, Duncan K. Evaluation of a nutrient starvation model of Mycobacterium tuberculosis persistence by gene and protein expression profiling. Mol Microbiol. 2002:43(3):717-31.

13. Hu Y, Mangan JA, Dhillon J, Sole KM, Mitchison DA, Butcher PD, et al. Detection of mRNA transcripts and active transcription in persistent Mycobacterium tuberculosis induced by exposure to rifampin or pyrazinamide. J Bacteriol. 2000;182(22):6358-65.

14. Shleeva MO, Bagramyan K, Telkov MV, Mukamolova GV, Young M, Kell DB, et al. Formation and resuscitation of "non-culturable" cells of Rhodococcus rhodochrous and Mycobacterium tuberculosis in prolonged stationary phase. Microbiology. 2002;148(Pt 5):1581-91.

15. Deb C, Lee CM, Dubey VS, Daniel J, Abomoelak B, Sirakova TD, et al. A novel in vitro multiple-stress dormancy model for Mycobacterium tuberculosis generates a lipid-loaded, drug-tolerant, dormant pathogen. PLoS One. 2009;4(6):e6077.

16. Sala C, Dhar N, Hartkoorn RC, Zhang M, Ha YH, Schneider $\mathrm{P}$, et al. Simple model for testing drugs against nonreplicating Mycobacterium tuberculosis. Antimicrob Agents Chemother. 2010;54(10):4150-8.

17. Salina EG, Mollenkopf HJ, Kaufmann SH, Kaprelyants AS. M. tuberculosis Gene Expression during Transition to the "Non-Culturable" State. Acta Naturae. 2009;1(2):73-7.

18. Shleeva MO, Kudykina YK, Vostroknutova GN, Suzina NE, Mulyukin AL, Kaprelyants AS. Dormant ovoid cells of Mycobacterium tuberculosis are formed in response to gradual external acidification. Tuberculosis (Edinb). 2011:91(2):146-54.

19. Biketov S, Potapov V, Ganina E, Downing K, Kana BD, Kaprelyants A. The role of resuscitation promoting factors in pathogenesis and reactivation of Mycobacterium tuberculosis during intra-peritoneal infection in mice. BMC Infect Dis. 2007:7:146

20. Salina EG, Waddell SJ, Hoffmann N, Rosenkrands I, Butcher PD, Kaprelyants AS. Potassium availability triggers Mycobacterium tuberculosis transition to and resuscitation from, non-culturable (dormant) states. Open Biol. 2014;4(10). doi:10.1098/rsob.140106.

21. Castaneda-Garcia A, Do TT, Blazquez J. The K+ uptake regulator TrkA controls membrane potential, pH homeostasis and multidrug susceptibility in Mycobacterium smegmatis. J Antimicrob Chemother. 2011;66(7):1489-98.

22. Cholo MC, Boshoff HI, Steel HC, Cockeran R, Matlola NM, Downing KJ, et al. Effects of clofazimine on potassium uptake by a Trk-deletion mutant of Mycobacterium tuberculosis. J Antimicrob Chemother. 2006;57(1):79-84.

23. Epstein $\mathbf{W}$. The roles and regulation of potassium in bacteria. Prog Nucleic Acid Res Mol Biol. 2003;75:293-320.

24. Young M, Mukamolova GV, Kaprelyants AS. Mycobacterial Dormancy and Its Relation to Persistence. In: Parish T, editor. Mycobacterium: Molecular Microbiology. UK: Horizon Bioscience; 2005. p. 265-320.

25. Salina E, Ryabova O, Kaprelyants A, Makarov V. New 2-thiopyridines as potential candidates for killing both actively growing and dormant Mycobacterium tuberculosis cells. Antimicrob Agents Chemother. 2014;58(1):55-60.

26. Wang Z, Gerstein M, Snyder M. RNA-Seq: a revolutionary tool for transcriptomics. Nat Rev Genet. 2009;10(1):57-63.

27. Diedenhofen B, Musch J. cocor: a comprehensive solution for the statistical comparison of correlations. PLoS One. 2015;10(3):e0121945.

28. Beste DJ, Peters J, Hooper T, Avignone-Rossa C, Bushell ME, McFadden J. Compiling a molecular inventory for Mycobacterium bovis BCG at two growth rates: evidence for growth rate-mediated regulation of ribosome biosynthesis and lipid metabolism. J Bacteriol. 2005;187(5):1677-84.

29. Cook GM, Berney M, Gebhard S, Heinemann M, Cox RA, Danilchanka O, et al. Physiology of mycobacteria. Adv Microb Physiol. 2009;55:81-182. 318-189.

30. Ingraham JL, Neidhardt FC. Escherichia coli and Salmonella: cellular and molecular biology. Washington, D.C.: ASM; 1996. 
31. Skjold AC, Juarez $\mathrm{H}$, Hedgcoth C. Relationships among deoxyribonucleic acid, ribonucleic acid, and specific transfer ribonucleic acids in Escherichia coli 15 T - at various growth rates. J Bacteriol. 1973;115(1):177-87.

32. Robinson MD, McCarthy DJ, Smyth GK. edgeR: a Bioconductor package for differential expression analysis of digital gene expression data. Bioinformatics. 2010:26(1):139-40.

33. Lew JM, Kapopoulou A, Jones LM, Cole ST. TubercuList-10 years after. Tuberculosis (Edinb). 2011;91(1):1-7.

34. Wattam AR, Abraham D, Dalay O, Disz TL, Driscoll T, Gabbard JL, et al. PATRIC, the bacterial bioinformatics database and analysis resource. Nucleic Acids Res. 2014;42(Database issue):D581-591.

35. Arnvig KB, Comas I, Thomson NR, Houghton J, Boshoff HI, Croucher NJ, et al. Sequence-based analysis uncovers an abundance of non-coding RNA in the total transcriptome of Mycobacterium tuberculosis. PLoS Pathog. 2011;7(11):e1002342.

36. Arnvig KB, Young DB. Identification of small RNAs in Mycobacterium tuberculosis. Mol Microbiol. 2009;73(3):397-408.

37. DiChiara JM, Contreras-Martinez LM, Livny J, Smith D, McDonough KA, Belfort M. Multiple small RNAs identified in Mycobacterium bovis BCG are also expressed in Mycobacterium tuberculosis and Mycobacterium smegmatis. Nucleic Acids Res. 2010;38(12):4067-78.

38. Miotto P, Forti F, Ambrosi A, Pellin D, Veiga DF, Balazsi G, et al. Genomewide discovery of small RNAs in Mycobacterium tuberculosis. PLoS One. 2012;7(12):e51950.

39. Pellin D, Miotto P, Ambrosi A, Cirillo DM, Di Serio C. A genome-wide identification analysis of small regulatory RNAs in Mycobacterium tuberculosis by RNA-Seq and conservation analysis. PLoS One. 2012;7(3):e32723.

40. Haning K, Cho SH, Contreras LM. Small RNAs in mycobacteria: an unfolding story. Front Cell Infect Microbiol. 2014;4:96.

41. Houghton J, Cortes T, Schubert O, Rose G, Rodgers A, De Ste CM, et al. A small RNA encoded in the Rv2660c locus of Mycobacterium tuberculosis is induced during starvation and infection. PLoS One. 2013:8(12):e80047.

42. Aanes H, Winata C, Moen LF, Ostrup O, Mathavan S, Collas P, et al. Normalization of RNA-sequencing data from samples with varying mRNA levels. PLoS One. 2014;9(2):e89158.

43. Loven J, Orlando DA, Sigova AA, Lin CY, Rahl PB, Burge CB, et al. Revisiting global gene expression analysis. Cell. 2012;151(3):476-82.

44. Bernstein JA, Khodursky AB, Lin PH, Lin-Chao S, Cohen SN. Global analysis of mRNA decay and abundance in Escherichia coli at single-gene resolution using two-color fluorescent DNA microarrays. Proc Natl Acad Sci U S A. 2002;99(15):9697-702.

45. Anderson KL, Dunman PM. Messenger RNA Turnover Processes in Escherichia coli, Bacillus subtilis, and Emerging Studies in Staphylococcus aureus. Int J Microbiol. 2009;2009:525491.

46. Hambraeus G, von Wachenfeldt C, Hederstedt L. Genome-wide survey of mRNA half-lives in Bacillus subtilis identifies extremely stable mRNAs. Mol Genet Genomics. 2003;269(5):706-14.

47. Rustad TR, Minch KJ, Brabant W, Winkler JK, Reiss DJ, Baliga NS, et al. Global analysis of mRNA stability in Mycobacterium tuberculosis. Nucleic Acids Res. 2013;41(1):509-17.

48. Segev E, Smith $Y$, Ben-Yehuda S. RNA dynamics in aging bacterial spores. Cell. 2012;148(1-2):139-49.

49. Voskuil MI, Visconti KC, Schoolnik GK. Mycobacterium tuberculosis gene expression during adaptation to stationary phase and low-oxygen dormancy. Tuberculosis (Edinb). 2004;84(3-4):218-27.

50. Keren I, Minami S, Rubin E, Lewis K. Characterization and transcriptome analysis of Mycobacterium tuberculosis persisters. MBio. 2011:2(3):e00100-00111.

51. Li SK, Ng PK, Qin H, Lau JK, Lau JP, Tsui SK, et al. Identification of small RNAs in Mycobacterium smegmatis using heterologous Hfq. RNA. 2013;19(1):74-84.

52. Tsai CH, Baranowski C, Livny J, McDonough KA, Wade JT, Contreras LM. Identification of novel sRNAs in mycobacterial species. PLoS One. 2013;8(11):e79411.

53. Gottesman S, McCullen CA, Guillier M, Vanderpool CK, Majdalani N, Benhammou J, et al. Small RNA regulators and the bacterial response to stress. Cold Spring Harb Symp Quant Biol. 2006:71:1-11.

54. Arnvig K, Young D. Non-coding RNA and its potential role in Mycobacterium tuberculosis pathogenesis. RNA Biol. 2012;9(4):427-36

55. Solans L, Gonzalo-Asensio J, Sala C, Benjak A, Uplekar S, Rougemont J, et al The PhoP-dependent ncRNA Mcr7 modulates the TAT secretion system in Mycobacterium tuberculosis. PLoS Pathog. 2014;10(5):e1004183.
56. Pelly S, Bishai WR, Lamichhane G. A screen for non-coding RNA in Mycobacterium tuberculosis reveals a cAMP-responsive RNA that is expressed during infection. Gene. 2012;500(1):85-92.

57. Shleeva M, Goncharenko A, Kudykina Y, Young D, Young M, Kaprelyants A. Cyclic AMP-dependent resuscitation of dormant Mycobacteria by exogenous free fatty acids. PLoS One. 2013;8(12):e82914.

58. Kaplan R, Apirion D. The fate of ribosomes in Escherichia coli cells starved for a carbon source. J Biol Chem. 1975;250(5):1854-63.

59. Zundel MA, Basturea GN, Deutscher MP. Initiation of ribosome degradation during starvation in Escherichia coli. RNA. 2009;15(5):977-83.

60. Davis BD, Luger SM, Tai PC. Role of ribosome degradation in the death of starved Escherichia coli cells. J Bacteriol. 1986;166(2):439-45

61. Trauner A, Lougheed KE, Bennett MH, Hingley-Wilson SM, Williams HD. The dormancy regulator DosR controls ribosome stability in hypoxic mycobacteria. J Biol Chem. 2012;287(28):24053-63.

62. Klein DJ, Moore PB, Steitz TA. The roles of ribosomal proteins in the structure assembly, and evolution of the large ribosomal subunit. J Mol Biol. 2004;340(1):141-77.

63. Borovinskaya MA, Pai RD, Zhang W, Schuwirth BS, Holton JM, Hirokawa G, et al. Structural basis for aminoglycoside inhibition of bacterial ribosome recycling. Nat Struct Mol Biol. 2007;14(8):727-32.

64. Ramage HR, Connolly LE, Cox JS. Comprehensive functional analysis of Mycobacterium tuberculosis toxin-antitoxin systems: implications for pathogenesis, stress responses, and evolution. PLoS Genet. 2009;5(12):e1000767.

65. Schifano JM, Edifor R, Sharp JD, Ouyang M, Konkimalla A, Husson RN, et al. Mycobacterial toxin MazF-mt6 inhibits translation through cleavage of $23 \mathrm{~S}$ rRNA at the ribosomal A site. Proc Natl Acad Sci U S A. 2013;110(21):8501-6.

66. Winther KS, Brodersen DE, Brown AK, Gerdes K. VapC20 of Mycobacterium tuberculosis cleaves the sarcin-ricin loop of 235 rRNA. Nat Commun. 2013;4:2796.

67. Brzozowska I, Zielenkiewicz U. Regulation of toxin-antitoxin systems by proteolysis. Plasmid. 2013;70(1):33-41

68. Connell ND. Mycobacterium: isolation, maintenance, transformation, and mutant selection. Methods Cell Biol. 1994;45:107-25.

69. De Man J. The probability of most probable numbers. Eur J Appl Microbiol Biotechnol. 1975;1(1):67-78.

70. Rustad TR, Roberts DM, Liao RP, Sherman DR. Isolation of mycobacterial RNA. Methods Mol Biol. 2009;465:13-21.

71. Belisle JT, Mahaffey SB, Hill PJ. Isolation of mycobacterium species genomic DNA. Methods Mol Biol. 2009;465:1-12.

72. Levin JZ, Yassour M, Adiconis X, Nusbaum C, Thompson DA, Friedman N, et al. Comprehensive comparative analysis of strand-specific RNA sequencing methods. Nat Methods. 2010;7(9):709-15.

73. Langmead B, Salzberg SL. Fast gapped-read alignment with Bowtie 2. Nat Methods. 2012;9(4):357-9.

74. Mortazavi A, Williams BA, McCue K, Schaeffer L, Wold B. Mapping and quantifying mammalian transcriptomes by RNA-Seq. Nat Methods. 2008;5(7):621-8

75. Carver T, Harris SR, Berriman M, Parkhill J, McQuillan JA. Artemis: an integrated platform for visualization and analysis of high-throughput sequence-based experimental data. Bioinformatics. 2012;28(4):464-9.

76. Young MD, Wakefield MJ, Smyth GK, Oshlack A. Gene ontology analysis for RNA-seq: accounting for selection bias. Genome Biol. 2010;11(2):R14.

77. Stover CK, de la Cruz VF, Fuerst TR, Burlein JE, Benson LA, Bennett LT, et al. New use of BCG for recombinant vaccines. Nature. 1991;351(6326):456-60.

78. Cannone JJ, Subramanian S, Schnare MN, Collett JR, D'Souza LM, Du Y, et al. The comparative RNA web (CRW) site: an online database of comparative sequence and structure information for ribosomal, intron, and other RNAs. BMC Bioinformatics. 2002:3:2.

79. Lamichhane G, Arnvig KB, McDonough KA. Definition and annotation of (myco)bacterial non-coding RNA. Tuberculosis (Edinb). 2013;93(1):26-9. 